\title{
UPDATE
}

\section{Update in Medical Education}

\author{
Shobhina G. Chheda, MD, MPH', Reena Karani, MD², Kathel Dunn, MSLS \\ Stewart Babbott, $M D^{4}$, and Carol K. Bates, $M D^{5}$
}

'Department of Medicine, Section of General Internal Medicine, University of Wisconsin Hospital and Clinics, School of Medicine and Public Health, Madison, WI, USA; ${ }^{2}$ Brookdale Department of Geriatrics, Samuel M. Bronfman Department of Medicine, Mount Sinai School of Medicine, New York, NY, USA; ${ }^{3}$ National Network of Libraries of Medicine, Middle Atlantic Region, New York University Medical Center, New York, NY, USA; ${ }^{4}$ General and Geriatric Medicine, University of Kansas Medical Center, Kansas City, KS, USA; ${ }^{5}$ Division of General Medicine and Primary Care, Beth Israel Deaconess Medical Center, Boston, MA, USA.

J Gen Intern Med 23(2):195-201

DOI: $10.1007 /$ s 11606-007-0457-0

(C) Society of General Internal Medicine 2007

A cademic general internists are integral medical educators across the entire continuum of learners. Medical education research allows us to incorporate best practices in curriculum development and assessment and to promote effective teaching behaviors. In this paper, we summarize selected articles chosen for presentation at the Update in Medical Education session at the 30th annual meeting of the Society of General Internal Medicine.

\section{METHODS}

In planning the search strategy for this update, we focused on several specific themes: competency education, curriculum development and evaluation, chronic disease management, simulation, medical errors, professionalism, quality of life (including work hours), training location (hospital vs ambulatory setting), hospital medicine, assessment of work (including selfreflection, portfolio, direct observation of concurrent care, clinical outcomes), and practice and behavioral outcomes. Subsequently, we performed an English-only search of PUBMED, limited to articles published in 2006 using the search strategy given in Table 5 of Appendix 1.

Authors rated each abstract based on relevance, impact, and scientific rigor. Articles were ranked by each author with the final articles selected based on consensus after a discussion centered on the questions "Is this relevant to academic General Internists?" and "Will this article change practice?"

Received July 31, 2007

Revised October 15, 2007

Accepted October 22, 2007

Published online December 21, 2007

\section{RESULTS}

Our search strategy yielded 525 articles. The final 10 articles we selected fall into 3 themes: (1) teaching and feedback, (2) technology, simulation, and education, and (3) education and patient outcomes.

\section{TEACHING AND FEEDBACK}

Menachery EP, Knight AM, Kolodner K, Wright SM. Physician characteristics associated with proficiency in feedback skills. J Gen Intern Med. 2006; 21:440-46.

Feedback promotes learning as it facilitates reflection and serves as an impetus for performance improvement. Previous studies have shown that learners are not satisfied with the quality and quantity of feedback they receive. ${ }^{1,2}$ Identifying characteristics that are associated with proficiency in feedback may help programs develop targeted interventions to improve faculty skills. This HRSA-funded study sought to develop a measure of feedback skill and identify characteristics of physician teachers that are associated with high levels of proficiency with feedback.

In this 2002 cross-sectional study, 363 physicians who were either past participants of the Johns Hopkins Faculty Development Program (JHFDP) or members of a comparison group matched by age, gender, and job description were surveyed by mail. While the survey instrument was developed to assess the long-term outcomes of the JHFDP, 7 questions dealt specifically with behaviors or self-assessed proficiencies related to providing, eliciting, or reflecting on feedback. Response rate to the survey was $82 \%$ (299 of 363), but because the authors were interested in characteristics of teaching physicians associated with high levels of proficiency in feedback, they limited analysis to those who had been active teachers in the year preceding the survey $(N=262)$.

The authors developed a composite feedback scale using the 7 questions that specifically addressed feedback. The lowest possible score on this scale was 2 , while the highest was 30 ; the internal reliability using Cronbach's $\alpha$ was 0.76. Of the 262 active teachers, 254 completed all 7 questions and had a median score of 19 (range 8-30). The scale was then dichotomized at the median. Those physicians (53\%) who scored below were considered "low scorers", while those equal to or above the 
median (47\%) were considered "high scorers". Multivariable logistic-regression models were then used to identify independent associations between survey variables and "high" versus "low" feedback scorers. Six items, representing discrete faculty responses to survey questions, were found to be independently associated with high feedback scores. These physician characteristics included frequently attempting to detect and discuss the emotional responses of learners (odds ratio $[\mathrm{OR}]=4.6,95 \%$ CI 2.2-9.6), proficiency in handling conflict (OR=3.7, 95\% CI 1.5-9.3), frequently asking learners what they desire from the teaching interaction $(\mathrm{OR}=3.5,95 \% \mathrm{CI} 1.7-7.2)$, having written down or reviewed professional goals in the prior year $(\mathrm{OR}=3.2$, 95\% CI 1.6-6.4), frequently working with learners to establish mutually agreed upon goals, objectives, and ground rules $(\mathrm{OR}=$ 2.2, 95\% CI 1.1-4.7), and frequently letting learners figure things out themselves, even if they struggle $(\mathrm{OR}=2.1,95 \% \mathrm{CI}$ 1.1-3.9). As these characteristics were associated with high self-reported proficiency in feedback skills, the authors of this study recommend that faculty development programs promote these behaviors and skills as a way to impact feedback performance among faculty.

Study limitations include being based on a single site, and using self reported proficiency; in addition, the cross-sectional nature of the study provides only evidence of association and not causality. Finally, the feedback scale itself lacks predictive validity evidence.

In conclusion, this study provides evidence that certain teaching behaviors may be associated with higher levels of selfreported proficiency in giving feedback. Targeted interventions to facilitate these behaviors may be valuable.

Boehler ML, Rogers DA, Schwind CJ, Mayforth R, Guin J, Williams RG, Dunnington G. An investigation of medical student reactions to feedback: a randomized controlled trial. Med Educ. 2006; 40:746-49.

While techniques for providing feedback have been developed and much faculty development has focused on improving feedback, learners remain dissatisfied with the feedback they receive. ${ }^{3}$ This study evaluated learning outcomes and perceptions in students who received feedback compared to those who received general compliments.

This randomized controlled trial assessed the impact of compliments versus constructive feedback on both student satisfaction and student performance. Thirty-three second and third year medical students, recruited via e-mail solicitation from a single institution, were given instruction from 1 surgeon on 2-handed surgical square knots. The students were then randomized into one of 2 groups to receive either compliments which were prearranged and prescripted or specific, objective and timely constructive feedback based on an observed deficiency. Equal time was spent giving either compliments or constructive feedback. Both interventions were performed by the same surgeon that conducted the teaching.

Student performance was assessed through blinded review by 3 faculty evaluators. Three videotapes of all participants from baseline (pretest, before any instruction), post-instruction (after teaching from surgeon) and post-intervention (after either compliments or constructive feedback) were rated using a validated assessment instrument. ${ }^{4}$ The instrument allowed for a range in total score from $0-32$.

There were no differences between the two groups of students in demographics or experience level. The inter-rater
Table 1. Performance and Satisfaction Ratings in Students Receiving Compliments Versus Feedback

\begin{tabular}{lrrrr}
\hline \hline & \multicolumn{2}{l}{$\begin{array}{l}\text { Performance } \\
\text { Rating (Range Allowed 0-32) }\end{array}$} & & $\begin{array}{l}\text { Satisfaction } \\
\text { Rating }\end{array}$ \\
\cline { 2 - 4 } & Pretest & Pre-intervention & Posttest & \\
\hline Compliment & 5.82 & 15.39 & 17.00 & 6.0 \\
Feedback & 6.45 & 15.87 & 21.98 & 5.0 \\
$P$ value & .670 & .822 & .008 & .005 \\
\hline
\end{tabular}

reliability exceeded 0.8 for videotape ratings. Students receiving constructive feedback experienced greater performance improvement compared to the compliment group (17.00 vs 21.98, $P=.008$, Table 1), while students receiving compliments had higher levels of satisfaction with their feedback (6.0 vs 5.0, $P=.005$, Table 1).

This study had several limitations. It was a single center trial with a small sample size. Equivalent time was spent giving compliments or constructive feedback, and this may have led to a more abbreviated and perhaps abrasive quality of the constructive feedback, leading to negative impact on satisfaction. A motor skill was studied, and this may or may not be applicable to cognitive skills.

In conclusion, this study suggests that feedback focused on observed deficiencies improves performance, but may decrease learner satisfaction with feedback. Reliance on satisfaction ratings may miss this important outcome of feedback and, therefore, is an inappropriate measure of quality of feedback. As faculty, we should consider using both feedback and compliments to impact both student performance and student satisfaction.

Guarino CM, Ko CY, Baker LC, Klein DJ, Quiter ES, Escarce JJ. Impact of instructional practices on student satisfaction with attendings' teaching in the inpatient component of internal medicine clerkships. J Gen Intern Med. 2006; 21:7-12.

Greater instructor involvement with students has been shown to result in higher student satisfaction in internal medicine clerkships. ${ }^{5}$ Students value specific attitudes such as interest in teaching, respect for opinions, and availability in their highly rated attendings. ${ }^{6}$ In this study funded by RAND, the authors sought to identify specific attending teaching practices that affect student satisfaction with the quality of teaching on the inpatient component of the internal medicine clerkship.

A nationwide survey of a random sample of 2,250 fourth year medical students from 121 US medical schools from the AAMC database was conducted. The survey was designed by physicians and health service researchers based on a review of the literature, focus groups with students, and interviews with medical school faculty involved in clinical education of medical students. The survey asked questions regarding student satisfaction with teaching from inpatient attendings and frequency of specific teaching practices. The survey was piloted on 250 students and refined using a cognitive testing process. Questions were grouped conceptually into 4 categories: (1) attending teaching practices; (2) behaviors in the IM clerkship; (3) organizational features of the clerkship, and (4) student satisfaction with quality of teaching by attendings. The final survey was administered in the spring of 2002. Efforts to enhance 
response rate included multiple mailings, telephone follow up, and a monetary incentive of $\mathbf{\$} 40$.

The response rate was $63.8 \%(N=1,530)$. The average age of respondents was 28 , the majority were white, and fewer than $50 \%$ were women. There were no differences between responders and nonresponders with respect to age, race/ethnicity, and MCAT score.

The frequency of teaching practices and behaviors is presented in Table 2. Attending physician practices associated with satisfaction included engaging students in discussion regarding differential diagnosis, pathophysiology, and management; giving spontaneous talks; and giving planned talks (Table 3). Seeming eager or rushed to finish rounds was associated with lower satisfaction.

This study has several limitations. Students were asked to consider attendings as a "group" when reporting on their behavior. There was no direct evaluation of attending physician behavior; rather, this study was based on student report of behavior. Lastly, there was no measure of subsequent student clinical performance.

In conclusion, ward attendings may maximize student satisfaction if we engage students in meaningful discussions on differential diagnosis, pathophysiology, and patient care. Giving prepared and spontaneous talks can also modestly impact student satisfaction. Awareness that appearing rushed negatively impacts student satisfaction should lead us to consider incorporating behaviors to appear unrushed that we use with patients, such as time to sit, making eye contact, and attention to nonverbal communication. ${ }^{7}$

Smith CA, Hart AS, Sadowski LS, Riddle J, Evans AT, Clarke PM, Ganschow PS, Mason E, Sequeira W, Wang Y. Teaching cardiac examination skills: a controlled trial of two methods $J$ Gen Intern Med. 2006;21:1-6.

Against a background of an overall decline in physical exam skills $^{8}$ and the observation that less effective skills may contribute to diagnostic errors, ${ }^{9}$ the authors sought to determine if structured teaching of bedside cardiac examination skills improves medical residents' examination technique and their identification of key clinical findings.

Eighty residents at a single University hospital were studied to assess acquisition of cardiovascular physical exam skills and

Table 2. Teaching Practices and Behaviors ( $N=1,530$ students)

\begin{tabular}{llll}
\hline \hline Practice/Behavior & $\begin{array}{l}\text { Never/ } \\
\text { Rarely (\%) }\end{array}$ & $\begin{array}{l}\text { Sometimes } \\
(\%)\end{array}$ & $\begin{array}{l}\text { Often/ } \\
\text { Always (\%) }\end{array}$ \\
\hline $\begin{array}{l}\text { Engaging students in } \\
\text { substantive discussion } \\
\text { on patient care }\end{array}$ & 7 & 31 & 62 \\
$\begin{array}{l}\text { Gave prepared } \\
\text { presentation on topic }\end{array}$ & 34 & 45 & 21 \\
$\begin{array}{l}\text { Gave spontaneous } \\
\text { talk on topic }\end{array}$ & 13 & 36 & 50 \\
$\begin{array}{l}\text { Saw new patients with team } \\
\text { Seemed rushed to finish } \\
\text { rounds }\end{array}$ & 34 & 15 & 51 \\
\end{tabular}

Hours/weeks spent with student outside of rounds/ formal teaching (mean SD) $2.6 \pm 2.7$

Adapted from Guarino CM, Ko CY, Baker LC, et al. Impact of instructional practices on student satisfaction with attendings' teaching in the inpatient component of internal medicine clerkships. J Gen Intern Med. 2006;21:7-12.
Table 3. Logistic Regression of Student Satisfaction with the Overall Quality of Teaching by Attendings in the IM Clerkship (Number of Observations $=1,318$ )

\begin{tabular}{ll}
\hline \hline Variable & Odds Ratio $(95 \% \mathrm{Cl})$ \\
\hline $\begin{array}{l}\text { Engaging students in substantive } \\
\text { discussion on patient care }\end{array}$ & $3.0(2.4-3.8)$ \\
Gave prepared presentation on topic & $1.8(1.4-2.4)$ \\
Gave spontaneous talk on topic & $1.6(1.3-1.9)$ \\
Saw new patients with team & $1.2(1.1-1.3)$ \\
Seemed rushed to finish rounds & $0.56(0.44-0.71)$ \\
\hline
\end{tabular}

Adapted from Guarino CM, Ko CY, Baker LC, et al. Impact of instructional practices on student satisfaction with attendings' teaching in the inpatient component of internal medicine clerkships. $J$ Gen Intern Med. 2006;21:7-12.

identification of key clinical findings using two different teaching methods: demonstration and practice (DP) or collaborative discovery (CD).

In DP, one or more residents performed a part of the exam and reported findings to the group. This was followed by faculty demonstration of standardized techniques. Faculty provided explicit perceptual criteria for identifying key findings, confirmed or corrected residents' findings, and observed residents' practicing techniques.

In $\mathrm{CD}$, all residents performed a specific part of the exam and reported observations to the group. Faculty facilitated reporting and highlighted areas of agreement and disagreement. The faculty member also sought descriptions of techniques and criteria learners used in observation and description, suggested standardization of examination techniques and explanations of explicit perceptual criteria and reconciled reports of observations. Finally, residents reexamined the patient using suggested methods.

All residents who were on ward rotations at a universityaffiliated public hospital during 2 different months were eligible to participate. In a single blinded format within a structure of 3 clinical firms, 1 received no additional intervention (control), 1 received DP, and 1 received $C D$. Three 2 -hour bedside sessions were delivered each month with real patients. Specific resident characteristics were assessed pre-intervention, faculty members were trained, and residents were assessed pre- and post-intervention via a 2 -station OSCE for both examination technique and determination of key clinical findings.

Resident pre-intervention scores on examination technique and identification of key clinical findings were similar. Postintervention, both DP and CD groups significantly improved $(P<.005)$ their technical examination skills compared with the control group (CD 10\% and DP 12\%; both equivalent to an additional 3 to 4 exam skills being performed correctly). Regarding identification of key clinical findings, compared with control, only $\mathrm{CD}$ showed a modest improvement, equivalent to the identification of an additional 2-key clinical findings $(P=.046)$.

Limitations of the study include single site, no randomization, a gold standard of experienced clinicians rather than echo or phonocardiography, and short time interval.

In conclusion, this study suggested that both teaching interventions improve residents' exam technique, but only $\mathrm{CD}$ improved the critical skill of identifying key findings. This may suggest a potential benefit of $\mathrm{CD}$ for improving learners' diagnostic decision-making. 


\section{TECHNOLOGY, SIMULATION, AND EDUCATION}

\section{Turner MK, Simon SR, Facemyer KC, Newhall LM, Veach TL.} Web-based learning versus standardized patients for teaching clinical diagnosis: a randomized, controlled, crossover trial. Teach Learn Med. 2006;18(3);208-14.

Newer methods of teaching clinical diagnosis skills include use of standardized patients and web-based methodologies. It is unclear which methods are most effective. This study sought to assess the efficacy, student preference, and cost of standardized patients and web-based formats for instruction in clinical diagnosis.

Thirty 2nd year medical students in a clinical problem solving course were randomized to either 45 minutes of webbased or standardized patient instruction in the evaluation of abdominal pain or headaches. The two groups then crossedover to the other instructional method for the second case. Checklists for history and physical findings, and structured review of SOAP notes were used. Feedback was given to the students 4 days after the teaching sessions.

Evaluation of student proficiency with headache and abdominal pain was done 4 weeks after the teaching sessions with a 2station OSCE. Common checklists of required history and physical exam elements were developed for each case. Blinded to student allocation, 2 trained faculty assessed the OSCE, and 2 other reviewers graded notes. These evaluations were reliable (Cronbach's alpha 0.68-0.69). Students also rated the formats, and costs were calculated for both teaching methods.

Web-based and standardized patient methods produced similar scores on both OSCEs (abdominal pain $66 \%$ vs $62 \%$; $P=.17$; headache $56 \%$ vs $63 \% ; P=.07$ ). Web-based training produced a higher score on the abdominal pain SOAP note ( $69 \%$ vs $47 \% ; P=.006)$, but not the headache SOAP note $(69 \%$ vs $67 \% ; P=.85)$ Students preferred the SP based instruction. Costs were similar for start-up, $\mathbf{\$} \mathbf{\$ 2 , 2 5 0}$ for web-based and $\$ 2,190$ for standardized patient) but less for web-based for ongoing use (\$30 web-based and $\$ 45$ for standardized patient).

Limitations included a small number of students at a single site, the short time period of study, and the fact that students could not be blinded to the intervention.

In conclusion, this study showed equivalency of standardized patients and web-based techniques for learner outcomes and comparable start-up costs. The web-based method was less expensive over time, but the standardized patient method was preferred by learners.

Cook DA, Thompson WG, Thomas KG, Thomas MR, Pankratz VS. Impact of self-assessment questions and learning styles in web-based learning: a randomized, controlled, crossover trial Acad Med. 2006;81:231-38.

Studies show that web-based learning (WBL) improves learning as much or more than traditional teaching methods ${ }^{10}$ or no intervention. ${ }^{11}$ Adding self-assessment questions to WBL has theoretical promise for improving learning, but the evidence is inconclusive. ${ }^{12}$ These authors sought to determine the effect of self-assessment questions on learners' knowledge and format preference in WBL. They also measured individual learning styles and sought associations between learning styles and outcomes.

In this study, 146 Internal Medicine residents from 1 academic medical center in 2003-2004 were randomized and crossed-over to receive either a traditional WBL module or "question-enhanced" WBL module for 4 different content areas. Traditional WBL modules on ambulatory medicine topics were part of the ambulatory clinic curriculum at the time of the study. Four modules, cervical cancer screening, dementia, osteoporosis, and dyspepsia, were selected for development of a "questionenhanced format". This consisted of case-based multiple choice with feedback answers. There was no new content, and layout was identical except for embedded questions.

Learning styles were assessed using Felder and Solomon's index of learning styles (ILS). Students were scored in 4 dimensions: (1) active-reflective; (2) visual-verbal; (3) sensingintuitive; and (4) sequential-global.

Two outcomes were measured: (1) knowledge via immediate and delayed (end of academic year) testing on each module and (2) format preference using a posttest questionnaire. The test consisted of case-based questions developed to address each module's learning objectives. The knowledge questions were reviewed by experts and piloted on internal medicine faculty. The preference questionnaire included 6-point Likert scale assessments of efficiency, effectiveness, and time spent.

Eighty-three percent of those recruited participated (121 of 146). Residents had higher knowledge scores immediately post-training using the question format $(78.9 \%$ correct vs $76.2 \%, P=.006$ ). However, this difference did not persist on delayed testing $(70.3 \%$ vs $69.9 \%, P=.77)$. Residents preferring the question format scored higher on immediate posttest than those preferring standard format $(79.7 \% \pm 1.1$ vs $69.5 \% \pm 2.3$ $P<.001)$. Only "verbal learners" differed in knowledge scores, scoring lower than visual-verbal intermediate or visual learners. Residents strongly preferred question format (83.3\%, 95\% CI 73.2-90.8\%). Residents reported that the question-based format was more efficient than standard $(71.4 \%$, 95\% CI $60.0-$ $81.2 \%$ ) format even though it was longer (60.4 vs 44.3 minutes).

This study has several limitations. Although actual questions were different, the case-based questions in the intervention group may have given learners an advantage on posttest casebased questions. This study took place at a single training program, and impact of the learning on actual patient care was not assessed.

In conclusion, interactive features such as adding questions to WBL improves immediate but not long-term learner knowledge. Verbal learners scored worse than visual or verbal-visual intermediate learners. Learners preferred the addition of casebased questions to modules despite requiring additional time.

Schilling K, Weicha J, Polineni D, Khalil S. An interactive web-based curriculum on evidence-based medicine: design and effectiveness. Fam Med. 2006;38:126-32.

The practice of evidence-based medicine (EBM) requires expertise in locating, evaluating, and applying evidence from the medical literature. This study reports on outcomes of a webbased EBM curriculum used to teach students in a Family Medicine Clerkship with learners scattered throughout the community.

This cohort trial alternated 6-week blocks of third year medical students between an intervention group receiving an online EBM curriculum and a control group without supplemental EBM. The study was done over a continuous 21-month period with 134 students enrolled in the intervention group and 104 students in the control group. 
The online EBM curriculum consisted of 4 separate learning prompts. The first online prompts were learning modules created by local medical librarians. The first focused upon MESH headings, explode and function commands, subheadings, and Boolean operators. The second module focused upon Cochrane databases and on gold standard literature including randomized controlled trials and meta-analyses. During week 4 , learners were directed to the National Guidelines Clearinghouse of the AHRQ, and in the fifth week, to the Michigan State University Department of Family Practice web site to read about the number needed to treat statistic. Students were assessed on the number of searches performed on the rotation, on their performance on a monitored literature search, and their ability to correctly calculate the number needed to treat. Student literature search performance was evaluated by medical librarians, blind to group, on the basis of the quality of evidence retrieved.

Students in the intervention group who conducted a significantly greater number of electronic searches (12.4 vs 2.6, $P<.05)$ were more likely to retrieve higher quality evidence $(60 \%$ vs $34 \%$ ) and were more likely to correctly calculate the number needed to treat ( $61 \%$ vs $22 \%$ ).

Study limitations included not evaluating EBM skills before the clerkship, not measuring the durability of learning and search behaviors, and lack of evaluation on the application of EBM skills on real patient decisions.

In conclusion, web-based curriculum delivery is an effective method to deliver EBM skills and web delivery can be used among learners scattered across community-based sites.

Wayne DB, Butter J, Siddall VJ, Fudala MJ, Wade LD, Feinglass $\mathbf{J}$, McGaghie wC. Mastery learning of advanced cardiac life support skills by internal medicine residents using simulation technology and deliberate practice. J Gen Intern Med. 2006; 21:251-56.

Medical simulation has become increasingly popular as a teaching methodology, particularly to teach surgical skills and to simulate crises in the operating room. ${ }^{13}$ Advanced cardiac life support (ACLS) skills are one of the few required procedural competencies in the most recent requirements of the American Board of Internal Medicine; however, it is difficult to ensure sufficient exposure to ACLS for individual learners given the infrequent occurrence of cardiac arrest. Previous studies have found frequent deviations from established ACLS protocols.

In this study, authors sought to reach a set standard of competency in ACLS skills among their learners with little variation between learners. The study was funded by an Illinois state grant program funding work in academic medical centers. Study subjects were PGY2 Internal Medicine residents at a single university-based program. All residents had completed the standard ACLS course at the start of their training. Each resident completed four, 2-hour simulator teaching sessions with focused practice. The four modules focused upon (1) procedures; (2) asystole, ventricular fibrillation, and pulseless electrical activity; (3) supraventricular and ventricular tachycardia; and (4) bradycardia. Teaching was done on the human patient simulator (HPS, Medical Education Technologies, Inc, Sarasota, FL). Pre- and post-evaluations were based upon casespecific checklists for each ACLS scenario with 17-30 scored items per scenario. Items were all equally weighted and were scored as either correct or incorrect/not done. The authors used previously validated mean passing score ranges of 71.5$76.6 \%$ for each scenario. ${ }^{14}$ Inter-rater reliability was assessed by videotape review on $20 \%$ of filmed simulation tests (kappa: 0.79-0.93). Outcomes measured were posttest proficiency score in ACLS protocols using these skills checklists and the time taken by each learner to achieve proficiency.

Thirty-three of 41 residents $(81 \%)$ achieved mastery in the standard 8 hours of teaching. The other 8 residents were able to do so with an additional 15-60 minutes of instruction. The authors demonstrated a $24 \%$ increase in checklist scores comparing pretest to posttest scores. They found no correlation with pretest ACLS scores or USMLE scores. They did find a correlation between posttest scores and the need for added training as those who needed additional time to achieve mastery had lower final checklist scores.

Although durability of learning was not assessed in this study, these authors published another manuscript that demonstrated durability 9 months after postsimulation testing in a separate cadre of residents in the same training program. ${ }^{15}$ There were some additional limitations of this single institution study. The minimal required training for mastery is unknown as the authors set a floor of 8 hours of training. More importantly, resident performance in actual ACLS situations was not assessed.

In conclusion, this study adds to the body of evidence that simulation is effective and is likely best practice in teaching and evaluating ACLS skills. The authors' validated checklists are ideal evaluation tools that can be easily exported. Finally, the authors demonstrated that additional practice time can bring trainees to mastery and may represent a small, but valuable, added time commitment.

Zabar S, Hanley K, Kachur E, Stevens D, Schwartz MD, Pearlman E, Adams J, Felix K, Lipkin M, Kalet A. "Oh! She doesn't speak English!” Assessing resident competence in managing linguistic and cultural barriers. $J$ Gen Intern Med. 2006;21:510-13.

Trained interpreters are important for culturally competent care of patients with limited English proficiency (LEP). Moreover, federal law mandates that federally funded health care facilities provide access to interpreters. ${ }^{16}$ This unfunded study sought to assess Internal Medicine (IM) residents' ability to conduct a medical encounter with an ad hoc standardized interpreter (SI) and a standardized patient (SP) with LEP using an observed structured clinical examination (OSCE).

Seventy-six IM residents from 1 US academic medical center participated in the 10-minute station as part of a 10-station clinical skill OSCE in 2003. Competencies for the station and case-specific interpreter skills were developed using literature and expert opinion. The scenario involved a 50-year-old Bengali-speaking patient (the SP) and her bilingual brother (the SI) who were recalled to the clinic for a positive fecal occult blood test. Residents were directed to review lab results and make an appropriate plan for follow-up colonoscopy with the patient. They had 10 minutes to complete the task and were observed by two faculty members. After the station, residents received feedback from faculty observers and the SP and SI.

Both SP and SI received training to standardize their case portrayal and received instruction on global satisfaction scale rating. Faculty reviewed and rated videotapes to enhance reliability before the study. Each resident was rated by two 
faculty and the SP or SI using specific skill and global assessment checklists. Internal reliability of the 20-item faculty checklist using Cronbach's $\alpha$ was 0.91 and inter-rater reliability had a Spearman's $P=.65$. The authors found that the SP/SI ratings correlated with faculty ratings and that poor global performance judged by the SP/SI was associated with poor performance on other OSCE cases judged by faculty overall assessment. Overall, $94 \%$ of residents found the experience to be realistic, and $92 \%$ found the difficulty of the scenario to be appropriate.

Study limitations include case specificity, concerns that the station may measure general communication as opposed to intercultural communication skills, and issues of whether performance in an observed low-fidelity environment is representative of actual performance during day to day care.

In conclusion, an OSCE station is a practical, relevant, and engaging performance-based assessment of resident skills in communicating with LEP patients and ad hoc interpreters.

\section{EDUCATION AND PATIENT OUTCOMES}

Houston TK, Wall T, Allison JJ, Palonen K, Willett LL, Keife CI, Massie FS, Benton EC, Heudebert GR. Implementing achievable benchmarks in preventive health: a controlled trial in residency education. Acad Med. 2006;81(7):608-16.

Assessment of residents' clinical performance is often subjective and usually not based on patient outcomes. ACGME's introduction of objective practice-based learning in its recent guidelines heightens the need and importance of implementing outcome-based research and evaluation within the residency training period.

The goal of the study was to introduce outcome-based research techniques to residency training through implementation of a preventive health curriculum coupled with performance data feedback in comparison with peer-based benchmarks. This quasi-experimental, controlled study included internal medicine and pediatric residents from 1 U.S. academic medical center. One group $(n=112)$ received the intervention in 2002-2003. The control group consisted of internal medicine and pediatric residents matched on residency track and post-graduate year $(n=96)$ who did not receive the intervention in 2000-2001. The curriculum had three feedback components: (1) a group feedback lecture, (2) standardized individual feedback in which an individual's baseline performance was provided and the educators provided positive reinforcement on defined clear behavioral objectives; and (3) an individual performance report, comparing them to their peers. Residents' performance was assessed on 6 auditable preventive health indicators (Table 4) using chart review.

There were statistically significant differences $(P<.05)$ from baseline to follow-up in the intervention group of internal medicine residents in 5 of 6 indicators (smoking screening, quit smoking advice, colon cancer screening, pneumonia vaccine, and lipid screening). There were no significant changes in the group. There were statistically significance differences $(P<.05)$ from baseline to follow-up in the intervention group of pediatric residents for 4 of 6 indicators ( car seats, eye alignment, parental quit smoking advice, and car restraints). There were no significant changes in the control group.

The limitations of the study were that it was not randomized, and the control group was not assessed simultaneously to the intervention group, but rather a group from the previous
Table 4. Auditable Preventative Health Indicators Chosen for Assessment of Resident Performance

\begin{tabular}{ll}
\hline \hline Medicine & Pediatrics \\
\hline Quit smoking advice & Parental quit smoking advice \\
Breast cancer screening & Parental smoking screening \\
Lipid screening & Car restraints (4 and older) \\
Smoking screening & Car seats (4 and younger) \\
Colon cancer screening & Eye alignment \\
Pneumonia vaccine & Immunization up to date \\
\hline
\end{tabular}

academic year was used. Also, it was conducted at 1 university and individual physician and patient characteristics may have confounded results. In this study, one is unable to distinguish between improvements in resident charting behaviors or provision of care behaviors. Costs were assessed at $\$ 107.00$ per trainee for training abstractors and baseline chart audit.

In conclusion, this study demonstrated an effective and relatively cost-efficient way of implementing an audit and feedback program which improved documentation and perhaps provision of preventive health care within residency training. Data used in audit and feedback of residents may be used to partially meet ACGME guidelines.

Conflict of Interest: None disclosed.

Corresponding Author: Shobhina G. Chheda, MD, MPH; Department of Medicine, Section of General Internal Medicine, University of Wisconsin, School of Medicine and Public Health, 600 Highland Avenue Room J5/222a, Madison, Wisconsin 53792-2454 (e-mail: sgc@medicine.wisc.edu).

\section{APPENDIX}

\section{REFERENCES}

1. Kogan J, Bellini LM, Shea JA. Have you had your feedback today. Acad Med.. 2000;75:1041.

2. Robins LS, Gruppen LD, Alexander GL, Fantone JC, Davis WK. A predictive model of student satisfaction with the medical school learning environment. Acad Med. 1997;72:134-9.

3. Irby DM. Teaching and learning in ambulatory care settings-a thematic review of the literature. Acad Med.. 1995;7010898-931.

4. Rogers DA, Regehr G, Gelula M, Yeh KA, Howdieshell T, Webb W. Peer teaching and computer assisted learning: an effective combination for surgical skill training. J Surg Res.. 2000;92153-5.

5. Ramsey PG, Gillmore GM, Irby DM. Evaluating clinical teaching in the medicine clerkship: relationship of instructor experience and training setting to ratings of teaching effectiveness. $J$ Gen Intern Med. 1988;34351-5.

6. Mazor KM, Stone SL, Carlin M, Alper E. What do medicine clerkship preceptors do best. Acad Med.. 2002;778837-40.

7. Teutsch C. Patient-doctor communication. Med Clin N Am. 2003; 87:1115-45.

8. Mangione S. Cardiac auscultatory skills of physicians-in-training: a comparison of three English-speaking countries. Am J Med. 2001; 110:210-6.

9. Wray NP, Friedland JA. Detection and correction of house staff error in physical diagnosis. JAMA.. 1983;249:1035-7.

10. Grundman J, Wigton, Nickol D. A controlled trial of an interactive, web-based virtual reality program for teaching physical diagnosis skills to medical students. Acad Med.. 2000;7510 supplS47-S49. 


\section{APPENDIX}

Table 5. English-Only Search of PUBMED, Limited to Articles Published in 2006

\begin{tabular}{|c|c|c|c|}
\hline Teaching/Education Themes & Study Methodology & Journals & $\begin{array}{l}\text { Medical } \\
\text { Education }\end{array}$ \\
\hline $\begin{array}{l}\text { Teaching [MeSH] or physician-patient } \\
\text { relations [MeSH] or professional role } \\
\text { [MeSH] or quality of life [MeSH] or job } \\
\text { satisfaction [MeSH] or ambulatory care } \\
\text { [MeSH] or hospitalization [MeSH] or } \\
\text { chronic disease [MeSH] or curriculum } \\
\text { [MeSH] or quality of health care [MeSH] } \\
\text { or medical errors [MeSH] OR teach* or } \\
\text { pedagog* or profession* or work hour } \\
\text { or work hours or work conditions or } \\
\text { quality of life or } 80 \text { hour or hospital } \\
\text { medicine or ambulatory care training or } \\
\text { chronic disease or reflect* or portfolio or } \\
\text { simulation or competency education } \\
\text { or clinical outcomes or behavioral } \\
\text { outcomes or practice outcomes or error } \\
\text { or curriculum development }\end{array}$ & $\begin{array}{l}\text { "Longitudinal studies"[MeSH] OR } \\
\text { "research"[MeSH] OR "randomized } \\
\text { controlled trials"[MeSH] or } \\
\text { multidisciplinary or multicenter } \\
\text { or "research"[MeSH terms] or } \\
\text { longitudinal or controlled or } \\
\text { research or "fellowships and } \\
\text { scholarships" or random } \\
\text { allocation or randomized }\end{array}$ & $\begin{array}{l}\text { Acad Med or Am J Med or Ann Intern } \\
\text { Med or Arch Intern Med or Br Med J } \\
\text { or JAMA or J Gen Intern Med or } \\
\text { Lancet or Med Educ or Med Teach } \\
\text { or N Engl J Med or Teach Learn Med } \\
\text { or Adv Health Sci Educ Theory } \\
\text { Pract or BMC Med Educ or Br J } \\
\text { Med Educ or Gerontol Geriatr Educ } \\
\text { or Health Educ Res or Acad Emerg } \\
\text { Med or Crit Care Med or Fam Med } \\
\text { or J Am Geriatr Soc or Med J Aust } \\
\text { or Artif Intell Med or BMC Med } \\
\text { Inform Decis Mak or Healthc Inform } \\
\text { or J Am Med Inform Assoc J Clin } \\
\text { Monit Comput or J Med Internet } \\
\text { Res or J Telemed Telecare or Med } \\
\text { Inform Internet Med or Telemed J E } \\
\text { Health or Intern Med J or J Intern } \\
\text { Med }\end{array}$ & $\begin{array}{l}\text { Education, } \\
\text { medical* [mesh] }^{*} \text { or students, } \\
\text { medical }\end{array}$ \\
\hline
\end{tabular}

*Education, medical includes CME, GME, undergraduate medical education, clinical clerkship and internship and residency

11. Lipman AJ, Sade RM, Glotzbach AL, Lancaster CJ, Marshall MF. The incremental value of Internet-based instruction as an adjunct to classroom instruction: a prospective randomized study. Acad Med. 2001;76:1060-64.

12. Swagerty D J, Studenski S, Laird, Rigler S. A case-oriented web-based curriculum in geriatrics for third-year medical students. J Am Geriatr Soc. 2000;48:1507-12.

13. Sutherland LM, Middleton PF, Anthony A, et al. Surgical simulation: a systematic review. Ann Surg.. 2006;243:291-300.
14. Wayne DB, Fudala MJ, Butter J, et al. Comparison of two standard setting methods for advanced cardiac life support training. Acad Med. 2005;80SupplS63-S66.

15. Wayne DB, Siddall VJ, Butter J, et al. A longitudinal study of internal medicine residents' retention of advanced cardiac life support skills. Acad Med. 2006;81:S9-S12.

16. Office of Minority Health. U.S. Department of Health and Human Services, National Standards of Cultural and linguistically Appropriate Services in Health Care, 2000. 